\title{
Respiratory obstruction secondary to adenotonsillar hypertrophy in HIV disease
}

\author{
Nelson C. Goldman ${ }^{1}$, J ames Cunningham², Dalys Castro² \\ 1. Department of Otolaryngology, University of Florida School of Medicine J acksonville, J acksonville, Florida, United States. \\ 2. Department of Radiology, University of Florida School of Medicine Jacksonville, J acksonville, Florida, United States.
}

Correspondence: Nelson C. Goldman, Associate Professor. Address: University of Florida School of Medicine J acksonville, 653-1 West Eighth St., Jacksonville, Florida 32209, United States. E-mail: nelson.goldman@jax.ufl.edu

Received: July 3, 2014

Accepted: September 18, 2014

Online Published: September 24, 2014

DOI : $10.5430 /$ crcp.v2n1p40

URL: http://dx.doi.org/10.5430/crcp.v2n1p40

\section{Abstract}

A 33 year old female with Human Immunodeficiency Disease (HIV) presented with upper respiratory obstruction secondary to adenotonsillar hypertrophy. Treatment with radiation therapy rather than surgery produced an excellent response.

\section{Key words}

Adenotonsillar hypertrophy, Radiation therapy

\section{I ntroduction}

Upper Respiratory obstruction due to hypertrophy of the tonsils and adenoids is often seen in clinical practice and may be the presenting symptom in Human Immunodeficiency Disease (HIV). A high index of suspicion is needed for adequate diagnosis and treatment. Radiation therapy has been shown to be beneficial eliminating the need for surgery.

\section{Case report}

A 33 year old female was seen in the otolaryngology clinic with several month's history of inability to breathe through her nose, anosmia and a nasal quality of voice. She had noticed increasing nasal congestion for two years. History revealed that she was HIV positive. Examination revealed the nasopharynx to be completely filled with an irregular, lymphoid appearing mass. She was unable to breathe through her nose. Oral cavity exam revealed marked hypertrophy of the tonsils with forward displacement of the uvula (see Figure 1). There was no cervical lymphadenopathy. A CT scan demonstrated a soft tissue mass filling the nasopharynx with extension into the nasal cavity (see Figure 2, 3). Biopsy of the mass revealed follicular hyperplasia with no evidence of tumor (see Figure 4). The patient was treated with radiation therapy with $6 \mathrm{mv}$ photons in $1.8 \mathrm{y}$ fractions for 17 days for a total dose of 30.6 Gray. She is asymptomatic three years post treatment. 
Figure 1. Diffuse enlargement of the tonsils which nearly meet in the midline and displace the uvula anteriorly.

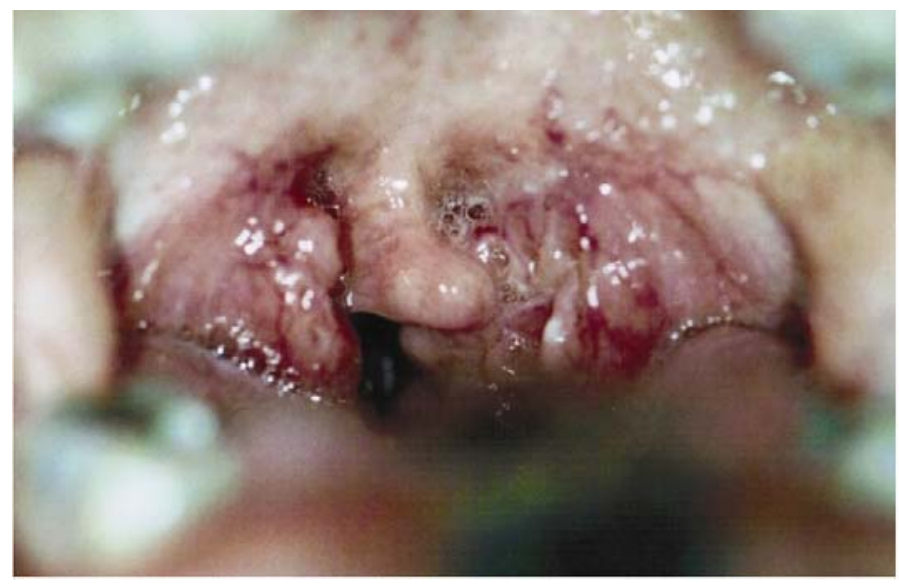

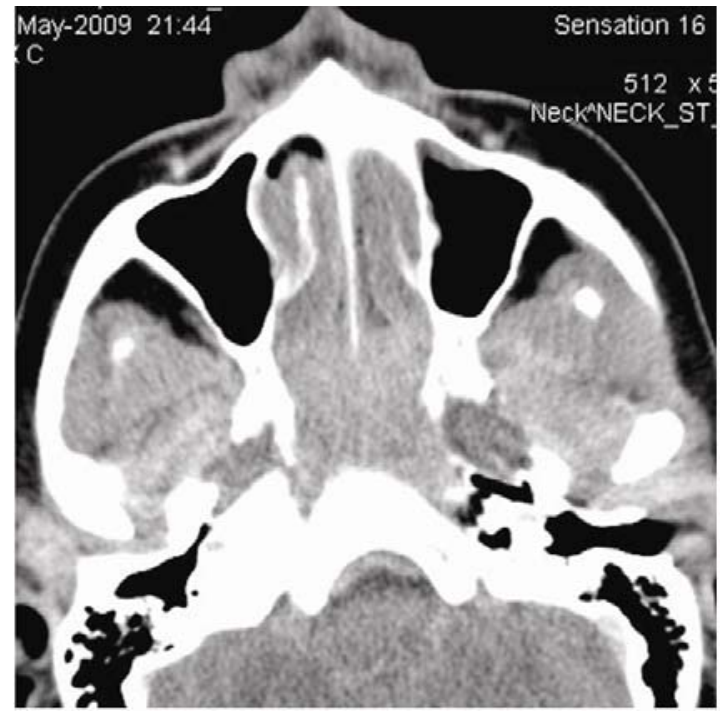

Figure 2. Axial image from CT soft tissue of the neck shows soft tissue density filling the nasal cavity without osseous changes.

Figure 4. Biopsy of nasal cavity shows diffuse follicular hyperplasia.

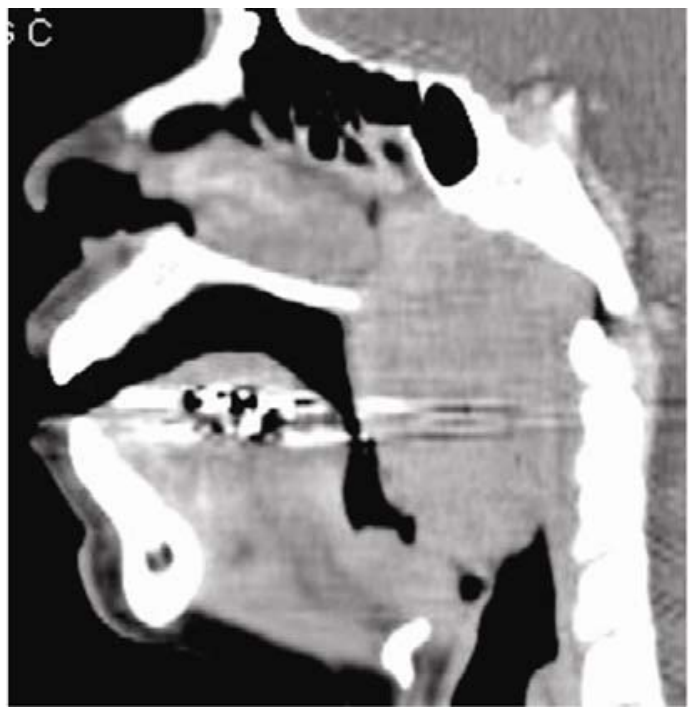

Figure 3. Sagittal image from CT soft tissue of the neck shows soft tissue density filling the nasal cavity extending posteriorly filling the nasopharynx.

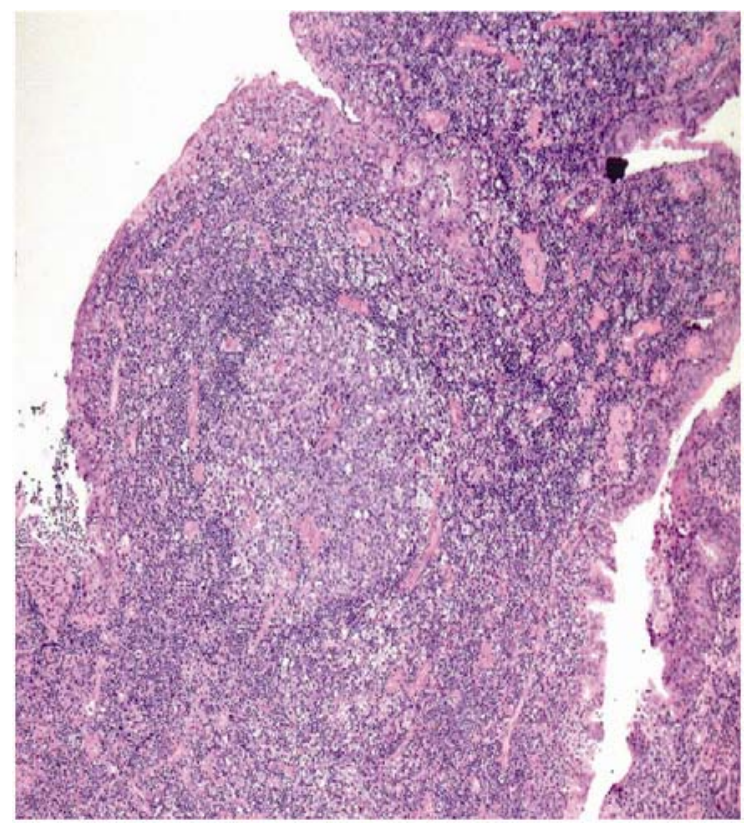




\section{Discussion}

Lymphoid hyperplasia in the head and neck region may be the presenting factor in HIV disease. The incidence of symptomatic lymphoid hyperplasia ranges from $45 \%-85 \%{ }^{[1,2]}$. The other manifestations of HIV in the head and neck include malignancies such as Kaposi's sarcoma, lymphoma, and carcinoma as well as opportunistic infections. The clinical presentation of adenotonsillar hypertrophy in a non-pediatric patient warrants consideration of undiagnosed HIV. When symptomatic, adenotonsillar hypertrophy with HIV is associated with nasal obstruction, recurrent tonsillitis and recurrent otitis media. The lymphoid hyperplasia of Waldeyer's ring may be dramatic and cause airway obstruction and dyspnea as in our patient. Hematogenous spread or direct inoculation of the mucosa of the upper airway may account for the hyperplasia seen in HIV which is present during the acute and symptomatic phase of the infection ${ }^{[3]}$. Adenoidal hypertrophy early in HIV is almost always benign, however, malignant transformation has been described. Malignant transformation is usually seen when the CD4+ count is less than $100 \mathrm{cells} / \mathrm{ml}{ }^{[4]}$. The diagnosis is made by an index of suspicion on physical examination and biopsy and not on CD4+ count alone. Histologically, multinucleated giant cells are not usually found within the mucosa associated lymphoid tissue and may play a specific role in the development of HIV associated lymphoid hyperplasia. Multinucleated giant cells were present in $67 \%$ of biopsy samples of HIV patients with lymphoid hyperplasia. Their presence should suggest the possibility of an underlying HIV infection ${ }^{[5]}$. Treatment options in symptomatic patients with adenotonsillar hypertrophy have previously been limited to surgical resection. In our case, as in previous trials, good results have been obtained with low dose radiation therapy ${ }^{[6]}$.

\section{Conclusion}

Low dose radiation is effective treatment and an alternative to surgery for adenotonsillar hypertrophy associated with HIV.

\section{Acknowledgement}

We thank the Pathology Department of University of Florida Shands Jacksonville for their assistance in obtaining a digital image of the biopsy specimen.

\section{References}

[1] Kieserman SP, Stern J. Malignant transformation of nasopharyngeal lymphoid hyperplasia. Otolaryngol Head Neck Surg. 1995; 113: 474-6. http://dx.doi.org/10.1016/S0194-5998(95)70088-9

[2] Orenstein JM. Hyperplastic lymphoid tissue in HIV/AIDS: An electron microscopic study. Ultra Struc Path. 2008 ; $32: 161-9$. PMid: 18696402. http://dx.doi.org/10.1080/01913120802179408

[3] Wenig BM, Thompson LD, Frankel SS, et al. Lymphoid changes of the nasopharyngeal and palatine tonsils that are indicative of human immunodeficiency virus infection: A Clinicopathologic study of 12 cases. Am J Surg Path. 1996; 20: 572-87. PMid: 8619422. http://dx.doi.org/10.1097/00000478-199605000-00004

[4] Cummings: Otolaryngology: Head and Neck Surgery, 4th Edition. Cervical adenopathy in the setting of HIV infection.

[5] Dargent JL, Lespagnard L, Kornreich A, et al. HIV-associated multinucleated giant cells in lymphoid tissue of the Waldeyer's Ring: A detailed study: Mod Pathol. 2000; 13(12): 1293-1299. PMid: 11144925. http://dx.doi.org/10.1038/modpathol.3880237

[6] Grobbelaar J, Seedat RY, Claassen AJ, et al. Low dose radiotherapy for adenotonsillar lymphoid hyperplasia in HIV-positive patients: Eur Arch Otorhinolaryngol. 2008; 265: 947-950. PMid: 18176811. http://dx.doi.org/10.1007/s00405-007-0573-9 